J. Agronomy \& Crop Science 186, 175-182 (2001)

(C) 2001 Blackwell Wissenschafts-Verlag, Berlin

ISSN 0931-2250

Queensland Department of Primary Industries, Kingaroy, Queensland, Australia

\title{
Rapid Assessment of Specific Leaf Area and Leaf Nitrogen in Peanut (Arachis hypogaea L.) using a Chlorophyll Meter
}

\author{
R. C. Nageswara Rao, H. S. Talwar and G. C. Wright \\ Authors' addresses: Dr R. C. Nageswara Rao (corresponding author; e-mail: rachapn@dpi.qld.gov.au) and Dr G. C. Wright, \\ Queensland Department of Primary Industries, Kingaroy, PO Box 23, Queensland 4610, Australia; Dr H. S. Talwar, Genetic \\ Resources and Enhancement Program, International Crops Research Institute for the Semi-Arid Tropics (ICRISAT), \\ Patancheru, Andhra Pradesh, PO 502 324, India
}

With 3 figures and 1 table

Received August 2, 2000; accepted January 9, 2001

\begin{abstract}
The present study investigates the potential use of a hand-held portable SPAD chlorophyll meter for rapid assessment of specific leaf area (SLA) and specific leaf nitrogen (SLN), which are surrogate measures of transpiration efficiency (TE) in peanut (Arachis hypogaea L.). The effects of sampling (leaf position, time of sampling and leaf water status) and climatic factors (solar radiation and vapour pressure deficit, VPD) on SLA and SPAD chlorophyll meter reading (SCMR) were studied in a range of peanut genotypes grown under field and greenhouse conditions. The correlation between SLA and SCMR was significant $(\mathrm{r}=-0.77, \mathrm{P}<0.01)$ for the second leaf from the apex but the correlation declined for leaves sampled from lower nodal positions. The diurnal fluctuation in SLA ranged from $-20 \%$ to $+10 \%$, whereas SCMR was relatively unaffected by these diurnal changes. Solar radiation and VPD during the sampling period had a significant influence on the relationship between SLA and SCMR, largely through their effects on SLA. However, standardization of SLA for these environmental factors significantly improved the relationship between SLA and SCMR from -0.50 to $-0.80(\mathrm{P}<0.01)$, suggesting that, when protocols for leaf sampling and SLA measurements are followed, SCMR can be a surrogate measure of SLA. There were significant relationships between SLN and SCMR $(\mathrm{r}=0.84, \quad \mathrm{P}<0.01)$ and SLN and SLA $(\mathrm{r}=-0.81$, $\mathrm{P}<0.01)$. These significant interrelationships amongst SLA, SLN and SCMR suggested that SCMR could be used as a reliable and rapid measure to identify genotypes with low SLA or high SLN (and hence high TE) in peanut.
\end{abstract}

Key words: peanut - SPAD chlorophyll meter - specific leaf area - specific leaf nitrogen specific leaf weight - transpiration efficiency

\section{Introduction}

Peanut is an economically important crop because of its widespread commercial production and utilization as oil, food and fibre. Over two-thirds of the global peanut production occurs in seasonally rain-fed regions, where drought is a potential constraint for crop production (Smartt 1994). Development of genetic and management strategies to alleviate the effects of drought on peanut has been a long-term goal of crop scientists. While breeding and selection for yield in a given drought environment are practical, the progress made in yield improvement using this approach has been slow and inconsistent due to the large genotype $\times$ environment $(\mathrm{G} \times \mathrm{E})$ interaction for yield (e.g. Branch and Hildebrand 1989, Cooper and Hammer 1996). This situation regarding crop improvement in peanut provides ample justification to search for additional selection criteria and novel and cost-effective selection tools to select genotypes with desirable traits for enhanced adaptation to drought-prone environments. Transpiration efficiency (TE, defined as $g$ of dry matter produced per $\mathrm{kg}$ of water transpired) is one such trait, which influences the performance of crops under waterlimited conditions. Variation in TE has been demonstrated among genotypes within crop species such as cotton (Gosyppium hirsutum) (Hubick and Farquhar 1987), peanut (Wright et al. 1994), cowpea (Vigna unguiculata L. Walp.) (Hall et al. 1992) and other grain legumes (White 1998). While being potentially useful, exploitation of germplasm for improved TE has not been possible because of practical difficulties associated with measurement of transpiration and root biomass under field 
conditions. A number of studies have shown a significant negative relationship ( $\mathrm{r}$ ranging from -0.88 to $-0.92, \mathrm{P}<0.01)$ between carbon isotope discrimination ratio $(\Delta)$ and TE in peanut in leaves, suggesting that $\Delta$ can be used as an indirect measure of TE in peanut (Hubick et al. 1986, Wright et al. 1988, 1994). While measurement of $\Delta$ is rapid, it is not economically feasible to apply this tool to the screening of large numbers of germplasm and segregating populations, particularly in developing countries.

Studies by Wright et al. (1994) and Nageswara Rao and Wright (1994) reported positive correlations $(\mathrm{r}=0.90-0.93, \mathrm{P}<0.01)$ between specific leaf area (SLA, ratio of leaf area to leaf dry weight) and $\Delta$, suggesting that SLA can be used as a surrogate measure of $\Delta$ (and hence TE) in peanut. Significant relationships between SLA and $\Delta$ $(\mathrm{r}=0.90-0.93, \quad \mathrm{P}<0.01) \quad$ (Wright et al. 1994), SLA and specific leaf nitrogen (SLN) $(r=-0.84$, $\mathrm{P}<0.01$ ) (Nageswara Rao and Wright 1994), and SLA and ribulose 1-5 di-phosphate carboxylase (Rubisco) $(\mathrm{r}=-0.81, \mathrm{P}<0.01)$ (Nageswara Rao et al. 1995) in independent studies suggested that photosynthetic capacity per unit leaf area is the major factor contributing to variation in TE in peanut. Although SLA is a trait that can be measured easily and cost-effectively, it is significantly influenced by factors such as time of sampling, leaf age (Wright and Hammer, 1994, Nageswara Rao et al. 1995) and the accuracy of the measurement. Similar environmental effects on SLA have been shown in soybean (Glycine max L. Merril) and wheat (Triticum aestivum L.) (Chatterton et al. 1972, Rawson et al. 1987). The variable strength of correlations ( $\mathrm{r}$ ranging from 0.71 to 0.94 ) between SLA and $\Delta$ found for a range of peanut genotypes and environments (Wright et al. 1996) indicates a need for further studies on the factors influencing SLA in peanut. The SPAD chlorophyll meter has recently been proposed to determine leaf nitrogen content non-destructively in a number of crops including maize (Zea mays L.) (Chapman and Barreto 1997), barley (Hordeum vulgare L.) (Araus et al. 1997) and tobacco (Nicotiana tabacum L.) (Mackown and Sutton 1998). To our knowledge, the utility of the SPAD chlorophyll meter as a selection tool for SLA or SLN (and hence TE) has, however, not been explored in peanut. If the chlorophyll meter could be used to estimate SLA and/or SLN in peanut, it could provide a rapid, low-cost and non-destructive technique to screen large breeding populations for TE. The aim of this study was to examine the relationships between SPAD chlorophyll meter readings, SLA and SLN in a range of peanut genotypes, and to assess the stability of these relationships across different environments.

\section{Materials and Methods}

Field and glasshouse trials were conducted during the postrainy (November-April 1997-98) and rainy (July-October 1998) seasons at the International Crops Research Institute for the Semi-Arid Tropics (ICRISAT) in India.

\section{Experimental material}

The 15 genotypes used in this study were grown in large multiplication blocks on an alfisol soil (Hyperthermic Lithic Rhodustalf) prepared in 1.2-m wide beds with $0.3-\mathrm{m}$ furrows $(0.15 \mathrm{~cm}$ deep $)$ on either side of the bed. The crops were adequately fertilized, irrigated and protected from pests and diseases throughout the growing period. In the greenhouse experiment, three genotypes (Chico, TAG 24 and CSMG 84-1) were grown in pots filled with a 2 : 1 sand-soil mixture, under adequately irrigated conditions. The pot experiment was laid out as a completely randomized design with each genotype sown in six replicate pots with two plants per pot.

\section{Measurements}

The unitless measurement obtained from the SPAD chlorophyll meter (SPAD-502, Minolta Corp., Ramsey, NJ) is based on the difference between light attenuation at $430 \mathrm{~nm}$ (the peak wavelength for chlorophyll $a$ and $b$ ) and that at $750 \mathrm{~nm}$ (near-infrared) with no transmittance. Thus, the SPAD chlorophyll meter readings (SCMR) represent the chlorophyll concentration in the leaf. The SCMRs were made on 50-60-day-old plants in the field trials. In an initial experiment, leaves were sampled from the nodal positions two, three and four below the apex on the main axis of five randomly selected plants from each of the three replications. Two SCMRs were recorded on each of the four leaflets of the tetrafoliate leaf. After recording the SCMR, the leaves were processed for the measurement of SLA. The leaf area of the four leaflets was measured using a LICOR 3100 leaf area meter after which the leaves were oven-dried at $80^{\circ} \mathrm{C}$ for at least $48 \mathrm{~h}$ before determining the leaf dry weight. The SLA was calculated as the ratio of leaf area to leaf dry weight. A number of preliminary studies were conducted to standardize methodology for SCMR and SLA measurement. Based on the results from these preliminary studies, only the fully expanded second leaf from the apex of the main axis was sampled during the morning period (0900-1100 h). The SCMRs were made on excised leaves in the laboratory, after which the leaflets were floated on water for at least $3 \mathrm{~h}$ prior to determining the SLA. While recording the SCMR, care was taken to ensure that the SPAD meter sensor fully covered the leaf 
lamina and that interference from veins and midribs was avoided. In order to study the SCMR-SLA relationship across contrasting environments, SLA was standardized for the total solar radiation $(\mathrm{R})$ incident on the crop and the vapour pressure deficit (VPD) that prevailed on the day prior to the sampling day. The SLA standardized for $\mathrm{R}$ $\left(\mathrm{SLA}_{\mathrm{R}}\right)$, VPD $\left(\mathrm{SLA}_{\mathrm{V}}\right)$ and both $\mathrm{R}$ and VPD $\left(\mathrm{SLA}_{\mathrm{RV}}\right)$ was computed as follows:

$\mathrm{SLA}_{\mathrm{R}}=\mathrm{SLA} / \mathrm{R}$

$\mathrm{SLA}_{\mathrm{V}}=\mathrm{SLA} / \mathrm{VPD}$

$\mathrm{SLA}_{\mathrm{RV}}=\mathrm{SLA} \times(\mathrm{R} / \mathrm{VPD})$

The elemental nitrogen content in the dried leaf samples was determined using the Kjeldahl digestion technique (Rayment and Higginson 1992). The $\mathrm{N}$ content was expressed as $\operatorname{SLN}\left(\mathrm{g} \mathrm{N} \mathrm{m}^{-2}\right.$ leaf area). Meteorological observations during the study were obtained from an automated weather station located at the ICRISAT campus.

\section{Results}

The purpose of the initial experiment was to examine the general relationship between SCMR and SLA in a range of 15 genotypes grown in the field. Leaves were sampled from the main axis, without paying much attention to the leaf nodal position, time of sampling during the day or weather conditions during the sampling period. The overall relationship between SLA and SCMR across the 15 genotypes was negative but not highly significant $(\mathrm{r}=-0.28, \mathrm{P}<0.05)$. Further analysis of the data revealed that the correlation between SCMR and SLA for individual genotypes was highly variable and ranged from 0.47 $(\mathrm{P}<0.05)$ to $0.79(\mathrm{P}<0.01)$, which was unexpected. Subsequent experiments examined the factors influencing the variability in the observed SCMR-SLA relationship in a range of peanut genotypes.

\section{SLA measurement}

Specific leaf area can be influenced by a number of factors affecting the leaf area or the dry weight of the sample. Most often, leaf folding and shrinkage associated with water deficits can contribute to significant error in SLA measurement by altering the potentially measurable leaf area. Preliminary experiments showed that floating leaves on water for $3 \mathrm{~h}$ prior to leaf area measurement resulted in substantial improvement in the strength of the relationship between SLA and SCMR. For instance, the correlation coefficient (r) for the SCMR-SLA relationship improved from -0.60 $(\mathrm{P}<0.05, \mathrm{n}=15)$ when SLA was measured without water treatment to $-0.75(\mathrm{P}<0.01, \mathrm{n}=15)$ when a 3-h water treatment prior to leaf area measurement was given. On the basis of these findings, leaves in subsequent experiments were floated on water for at least $3 \mathrm{~h}$ prior to determination of leaf area.

\section{Effect of leaf position}

In three genotypes (Chico, TAG 24 and CSMG 84-1) grown in the greenhouse, the relationship between SCMR and SLA was examined in leaves sampled from successive nodal positions (from the apex) on the main axis. The relationship was significantly stronger $(\mathrm{r}=-0.77, \mathrm{P}<0.01)$ for the leaves sampled from the second nodal position than for those from the other positions (Table 1). There was a trend for a decline in the strength of the SCMR-SLA relationship in the leaves sampled from lower nodal positions. It was interesting to note that the correlation coefficient and slope values were sharply reduced at lower nodal positions starting from the fourth leaf (from the apex), suggesting that fully expanded and mature leaves from the second nodal position were the most appropriate ones to use to develop a relationship with SCMR.

Table 1: Effect of leaf nodal position on the SCMRSLA relationship in peanut

\begin{tabular}{lccl}
\hline $\begin{array}{l}\text { Leaf number on } \\
\text { main axis from apex }\end{array}$ & $\mathrm{b}^{1}$ & $\mathrm{a}^{1}$ & $\mathrm{r}(\mathrm{n}=18)^{2}$ \\
\hline 1 & -3.94 & 370 & $-0.56^{*}$ \\
2 & -4.61 & 387 & $-0.77^{* *}$ \\
3 & -4.81 & 406 & $-0.62^{* *}$ \\
4 & -5.06 & 446 & $-0.56^{*}$ \\
5 & -4.58 & 400 & -0.50 \\
6 & -3.81 & 377 & $-0.57^{*}$ \\
7 & -3.17 & 341 & -0.53 \\
\hline
\end{tabular}

***Significant at the 0.05 and 0.01 probability levels, respectively.

${ }^{1}$ Regression coefficients for the SCMR-SLA relationship, SLA $=$ b(SCMR $)+a$.

${ }^{2}$ Each regression equation was derived from 18 data points ( 3 genotype $\times 6$ replications). 


\section{Diurnal variation in SCMR and SLA}

The diurnal changes in SLA and SCMR were examined in five genotypes (ICGS 76, ICG 476, TMV 2, CSMG 84-1 and ICGV 86031) grown during the 1997-98 post-rainy season under adequately irrigated conditions in the field. The measurements were made on a bright sunny day with solar radiation of about $24 \mathrm{MJ} \mathrm{day}^{-1}$. From each plot, 15 plants were randomly selected and leaves from the second nodal position on the main axis at $0830,1030,1230$ and $1500 \mathrm{~h}$ were sampled for SCMR and SLA measurements. The mean (over the day) SLA of genotypes ranged from $128 \mathrm{~cm}^{2} \mathrm{~g}^{-1}$ for ICGV 86031 to $194 \mathrm{~cm}^{2} \mathrm{~g}^{-1}$ for ICG 476, representing a significant difference among genotypes. However, there was a significant diurnal variation, with SLA deviating from -25 to $+10 \%$ from the genotypic mean (Fig. 1). Similar to SLA, the mean (over the day) SCMR ranged from 21.6 for ICG 476 to 36.7 for ICGV 86031, representing a significant genotypic variation. However, the deviation in SCMR from the genotypic mean (averaged over the four sampling times) was marginal and varied from -4 to $+4 \%$ only, with the deviation being greatest for the $0830 \mathrm{~h}$ measurement. These results indicated the relative

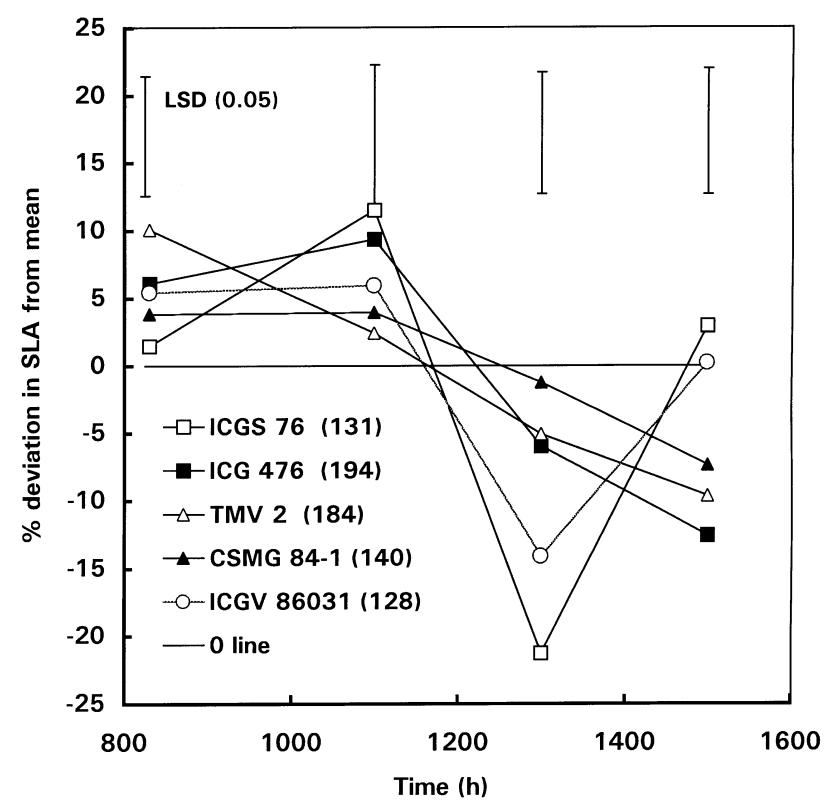

Fig. 1: Diurnal changes in SLA expressed as percentage deviation from the genotypic mean (over the day) in five peanut genotypes grown in the field. The values in parentheses adjacent to genotype legends denote the mean over the day for SLA. Vertical bars indicate LSD $(0.05)$ between genotypes at a given time insensitivity of SCMR to changes in the diurnal environment.

\section{Stability of SCMR-SLA relationship across genotypes and environments}

In an independent study, the effect of variable environmental conditions during leaf sampling on the SCMR-SLA relationship was examined in the 15 genotypes (used in the initial experiment) grown in large blocks in the field. Specific protocols developed from previous experiments for leaf sampling (second leaf from apex on main axis) and SLA measurement (with water treatment for $3 \mathrm{~h}$ ) were followed in making SCMR and SLA measurements. SPAD chlorophyll meter readings and SLA measurements were made on 10 plants sampled randomly (10 replications) from each plot at $0900-1100 \mathrm{~h}$ on 31 July and 17 August 1998. Daily weather conditions on the day prior to the sampling days differed significantly, with the incident total solar radiation and VPD being 17.3 $\mathrm{MJ} \mathrm{m}^{-2}$ and $1.1 \mathrm{kPa}$ on the first sampling day and $10.2 \mathrm{MJ} \mathrm{m}^{-2}$ and $0.86 \mathrm{kPa}$ on the second sampling day. The genotypic variation in SCMR ranged from 20 to 45, while the variation in SLA ranged from 125 to $250 \mathrm{~cm}^{2} \mathrm{~g}^{-1}$ (Fig. 2a). There was a significant $(\mathrm{r}=-0.7$ and $-0.84, \mathrm{P}<0.01)$ negative relationship between SCMR and SLA on each of the sampling dates, but the strength of the correlation was lower $(\mathrm{r}=-0.51, \mathrm{P}<0.05)$ when the data were pooled over the two sampling dates. It was apparent that the reduction in the strength of the relationship in pooled data (over the two sampling dates) was due more to variation in SLA than SCMR.

The effect of two major environmental variables, radiation $(\mathrm{R})$ and vapour pressure deficit (VPD), on the SCMR-SLA relationship was examined by standardizing the SLA for the R and VPD that prevailed a day before the leaf sampling. It was interesting to note that the negative relationship between SCMR and SLA improved significantly when SLA was standardized for the prevailing environmental conditions. The correlation between SCMR and SLA improved from $-0.51(\mathrm{P}<0.05)$ when SLA was not standardized to $-0.65,-0.73$ and $-0.80(\mathrm{P}<0.01)$ when SLA was standardized for $\mathrm{R}\left(\mathrm{SLA}_{\mathrm{R}}\right)$, VPD $\left(\mathrm{SLA}_{\mathrm{V}}\right)$ and a combination of $\mathrm{R}$ and VPD (SLA $\mathrm{W}_{\mathrm{W}}$ ), respectively. It was apparent from these results that use of SLA $\mathrm{W}_{\mathrm{W}}$ standardized the variation in SLA caused by the prevailing $R$ and VPD (Fig. 2b). 


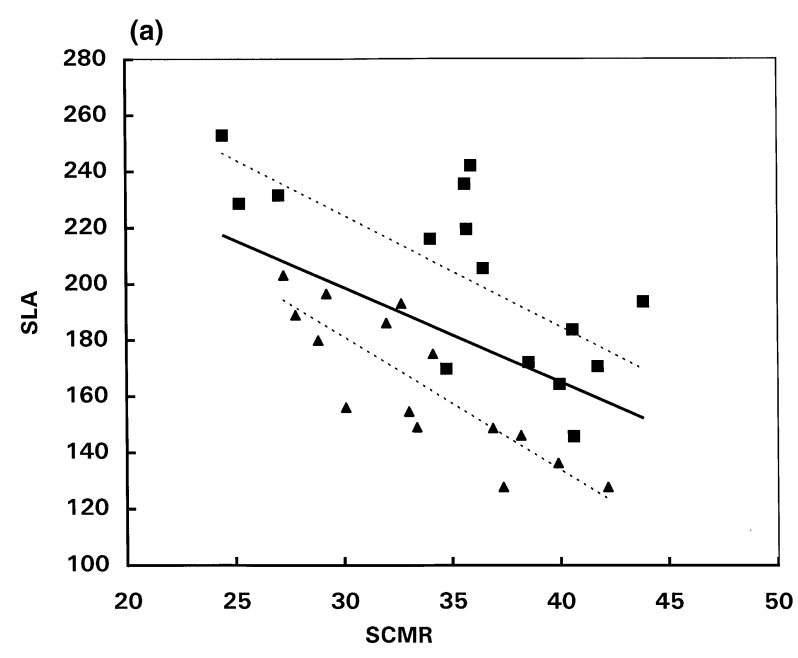

(b)

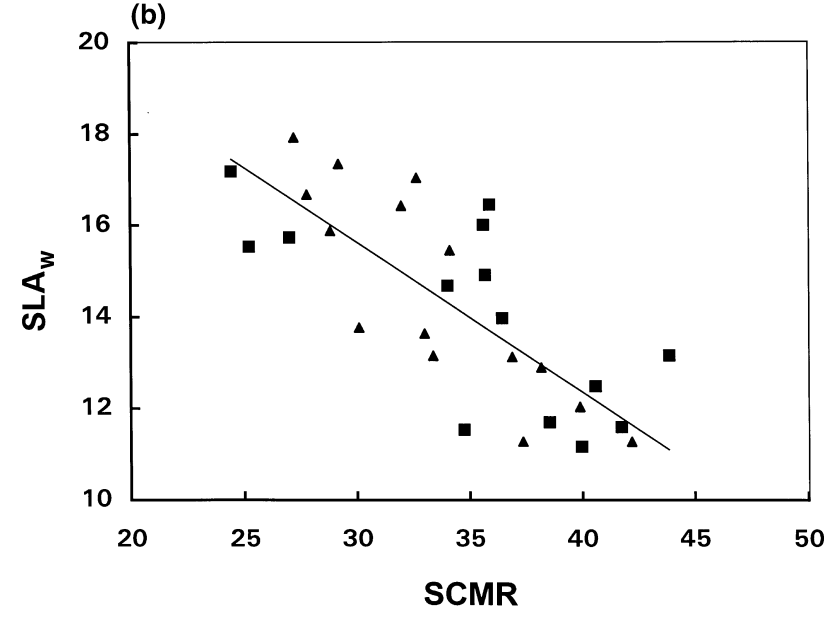

Fig. 2: (a) Relationship between SLA and SCMR measured at two sampling dates in 15 genotypes grown in a field experiment. The solid line indicates the overall regression line fitted using data from the two sampling dates $[\mathrm{SLA}=-3.36(\mathrm{SCMR})+299.74$; $\mathrm{r}=-0.50, \mathrm{P}<0.05]$, while dotted lines are regressions fitted using data from individual sampling dates, i.e. 31 July $1998[\boldsymbol{a}, \mathrm{SLA}=3.97(\mathrm{SCMR})+343.94, \mathrm{r}=-0.70$, $\mathrm{P}<0.01]$ and 17 August $1998 \quad[\mathbf{\Lambda}, \quad \mathrm{SLA}=$ $-4.75(\mathrm{SCMR})+323.8, \mathrm{r}=-0.84, \mathrm{P}<0.01]$. (b) Relationship between SLA adjusted for radiation and VPD $\left(\mathrm{SLA}_{\mathrm{W}}\right)$ and SCMR for 31 July 1998 (ם) and 17 August 1998 ( $\mathbf{\Delta})$ sampling dates (see a). The solid line indicates the regression fitted using data from both sampling dates $[\mathrm{SLA}=-0.33(\mathrm{SCMR})+25.46, \mathrm{r}=-0.80, \mathrm{P}<0.01]$

\section{Relationships amongst SLA, SLN and SCMR}

The elemental nitrogen content was determined in leaves of 15 genotypes sampled on 31 July 1998. The SLN ranged from 1.5 to $2.8 \mathrm{~g} \mathrm{~N} \mathrm{~m}^{-2}$, representing a significant genotypic variation. There was a significant negative relationship between SLA and SLN (Fig. 3a; r $=-0.81, \mathrm{P}<0.01$ ) and a positive relationship between the SCMR and SLN (Fig. 3b; $\mathrm{r}=0.84, \mathrm{P}<0.01$ ).

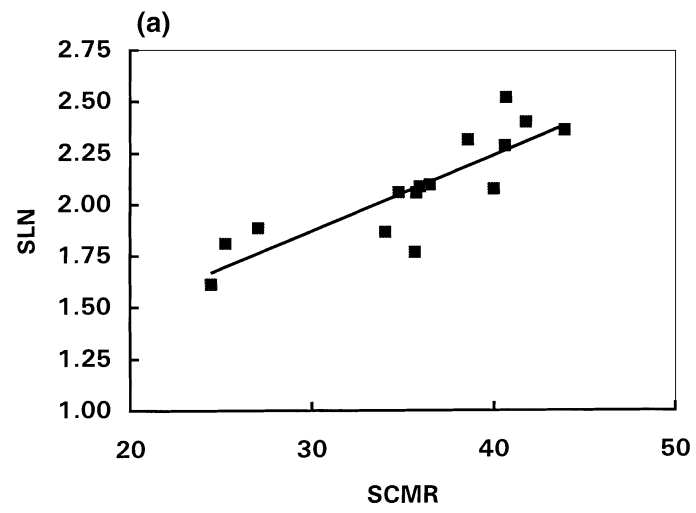

(b)

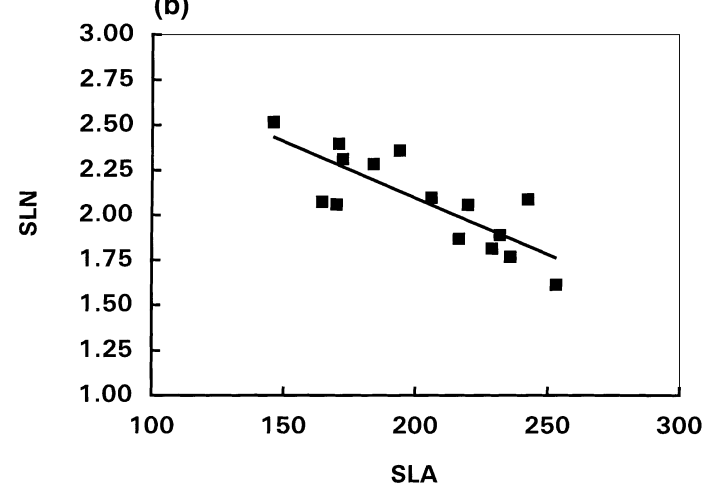

Fig. 3: Relationship of SLN with (a) SCMR [SLN = $0.037(\mathrm{SCMR})+0.769, \mathrm{r}=0.84, \mathrm{P}<0.01]$ and (b) SLA $[\mathrm{SLN}=-0.006(\mathrm{SLA})+3.36, \mathrm{r}=-0.81, \mathrm{P}<0.01]$, in 15 peanut genotypes in a field experiment

\section{Discussion}

The SPAD chlorophyll meter has been used to quantify chlorophyll concentration and leaf $\mathrm{N}$ in various crops such as rice (Oryza sativa L.) (Takebe et al. 1990), corn (Dwyer et al. 1995, Chapman and Barreto 1997) and wheat (Reeves et al. 1993). Leaf photosynthesis is generally correlated with chlorophyll content per unit leaf area, and hence the SPAD chlorophyll meter can provide a useful tool to screen for genotypic variation in potential photosynthetic capacity. Since TE in peanut is closely related to SLA and SLN, a rapid assessment of SLA or SLN using the SPAD chlorophyll meter might provide a rapid selection tool for these parameters. In our initial study, a poor and highly variable SCMR-SLA relationship was found among genotypes, indicating limited scope for the use of SCMR to assess SLA in peanut. Subsequent experiments, however, provided some improved understanding as to why this relationship varied across genotypes and environments. A number of factors contributed to the poor correlation, including (a) leaf position, (b) time of sampling (during 
the day), (c) errors in SLA measurement and (d) climatic conditions during the sampling period. It is also possible that genotypic differences in phenological development at the time of sampling could also have contributed to the variability in the SCMR-SLA relationship. Although the sampling was performed on 60-day-old plants, genotypic variation in reproductive development and hence variable demand for, and supply of, photosynthates from leaves cannot be ruled out. A significant effect of growth stage(s) on the relationship between SCMR and leaf photosynthesis has also been reported in soybean (Ma et al. 1995). The present study has also shown that the water status of leaves at the time of sampling can contribute to significant error in SLA measurement. This finding was supported by a significant improvement in the SCMR-SLA relationship following water treatment of leaves prior to SLA measurement.

It was apparent that the strength of the relationship between SCMR and SLA declined rapidly in leaves below the second nodal position (Table 1). Genotypic differences in leaf ageing, canopy structure and geometry, leading to variable light interception through canopies, could have contributed to the poor relationship between SLA and SCMR in lower leaves. Indeed, SLA was inversely correlated with incident light in a range of species (Friend et al. 1962, Friend 1966), including peanut (Wright and Hammer 1994). The diurnal variation in SLA (Fig. 1) may be linked with diurnal changes in starch content in leaves, which in turn can lead to changes in leaf dry weight. A strong association between SLA and starch content in leaves has been observed in soybean (Reddy et al. 1989). Rawson et al. (1987) argued that the diurnal changes in SLA could result from changes in demand for photosynthates from leaves to other active sinks in the plant. The 'active and passive' roles of the leaf as a reservoir for 'in transit' substrate bound for other growing parts within the plant (Rawson et al. 1987) could explain the observed -25 to $+10 \%$ diurnal changes in SLA (Fig. 1). In contrast, there were only minor diurnal fluctuations in SCMR, indicating that changes in chlorophyll concentration (and presumably SLN) were less affected by these transient diurnal changes in SLA. When appropriate protocols for sampling and SLA measurements had been implemented, the relationship between SCMR and SLA was significantly improved and consistent across experiments (Fig. 2a). Climatic conditions (radiation and VPD) during sampling had a significant influence on the SCMR-SLA relationship (Fig. 2a), with the environmental effects being mainly manifested on SLA rather than SCMR. It was interesting to note that the prevailing radiation and VPD during the sampling period could account for most of the variation in SLA (Fig. 2b). The influence of recent solar radiation environment on SLA has been shown in a number of other crops (Friend et al. 1962, Friend 1966, Reddy et al. 1989). Thus, the environmental effects on SLA observed in the present study might be associated with differences in the balance between assimilate production and utilization. Under certain environmental conditions the leaf (and hence SLA) could be acting as a temporary storage reservoir when synthesis of substrate in the leaves exceeds the demand from the other growing sinks. The influence of radiation and temperature on the production and utilization of photosynthates in peanut leaves has been clearly demonstrated (e.g. Bell et al. 1992). It could be hypothesized that, in its passive role (such as in leaves from the lower nodal positions), the leaf may serve as a temporary storage reservoir for assimilates and nutrients even though there is reduction in photosynthetic capacity. Wright and Hammer (1994) showed a gradual reduction in both SLN and specific leaf weight, SLW (inverse of SLA), from upper to lower leaves in peanut canopies, although the magnitude of this reduction from upper to lower leaves differed for SLN (34\%) and SLW $(25 \%)$. This variable level of reduction in SLN and SLW throughout the canopy could explain the observed reduction in the strength of correlation between SCMR and SLA in lower leaves of the peanut canopy (Table 1). However, further studies are needed to investigate the influence of environmental effects on passive and active roles of assimilate partitioning within the leaf, and hence provide improved understanding of the variation in the SCMR-SLA relationship.

The results from the present study suggest that, if SLA is to be used as a screening tool, then sampling should be performed on clear (full sunlight) days. Under high-radiation conditions, variation in SLA should be largely driven by photosynthetic capacity (Rawson et al. 1987), and hence it should be negatively correlated with photosynthesis and growth. Thus, genotypic differences in SLA as a consequence of photosynthetic capacity may be better expressed on days with high radiation. Our results also suggest that leaf sampling should be done at a set time during the day to avoid substantial diurnal variation in SLA. The present 
study has also shown that, for most accurate measurement of SLA, leaves should be sampled and measured at close to full turgidity, which requires floating of leaves on water prior to SLA measurement. However, with a large number of samples, this could be a very labour-intensive task. An alternate approach could be only to collect samples early in the morning when the leaves are at their maximum turgidity. The potential sampling errors associated with SLA measurement demonstrated here could explain much of the previously observed variation in the SLA and $\Delta$ relationship (Wright et al. 1996). As mentioned earlier, previous studies have shown that TE (and $\Delta$ ) variation in peanut is closely associated with photosynthetic capacity (Wright et al. 1988, Wright et al. 1994, Nageswara Rao and Wright 1994, Nageswara Rao et al. 1995). Although neither TE nor $\Delta$ was measured in the present study, the significant relationships amongst SCMR, SLA and SLN (Fig. 3a,b) imply that SCMR can be used to assess TE in peanut. The significant relationships amongst SCMR, SLA and SLN (Fig. 3a,b) and the relative insensitivity of SCMR to environmental effects surrounding the leaf (Figs 1 and 2a) suggest that SCMR could be used as a reliable and rapid measure to cull out genotypes with high SLA or low SLN (and hence poor TE) in breeding and selection programmes. The present study has also developed an improved understanding of the plant and environmental factors responsible for variation in the SCMR-SLA relationship. Results have shown that the major source of variation lies within the SLA component, and that SLA needs to be standardized to the prevailing radiation and VPD conditions so that the SCMR-SLA relationship can be applied across environments (Fig. 3b). The use of SPAD chlorophyll meter for indirect assessment of $\Delta$ (and hence TE) in a barley breeding programme has been shown to be effective (Araus et al. 1997).

\section{Zusammenfassung}

Rasche Messung der spezifischen Blattfläche und des Blattstickstoffs bei Erdnuß (Arachis hypogaea L.) unter Verwendung einer Chlorophyllmeßeinrichtung

Die vorliegende Arbeit untersucht das Anwendungspotential einer handgehaltenen, tragbaren SPAD-Chlorophyllmeßeinrichtung zur raschen Bestimmung der spezifischen Blattfläche (SLA) and des spezifischen Blattstickstoffgehaltes (SLN), welche die Messungen von TE (Arachis hypogaea L.) wiedergeben. Der Einfluß der Prob- enahme (Blattposition, Zeit der Probenahmen, Blattwasserstatus) und klimatischer Faktoren (Strahlung and VPD) auf SLA und SPAD Chlorophyllmessungen (SCMR) wurde an einer Reihe von Erdnußgenotypen, die im Feld und im Gewächshaus angezogen wurden, untersucht. Die Korrelation zwischen SLA und SCMR war für das zweite Blatt unterhalb der Spitze signifikant $(r=-0,77, \mathrm{P}<0.01)$; die Korrelation ging aber für Blätter unterer Knotenposition zurück. Die Tagesveränderungen lagen zwischen -20\% und $+10 \%$, wobei SCMR relativ unbeeinflußt von den Tagesschwankungen blieb. Strahlung und VPD hatten, insbesondere auf Grund ihrer Wirkungen auf SLA, während der Probenahmeperiode einen signifikanten Einfluß auf die Beziehungen zwischen SLA and SCMR. Eine Standardisierung von SLA für diese Umweltbedingungen verbesserten signifikant die Beziehungen zwischen SLA und SCMR von $-0,50$ bi $-0,80(\mathrm{P}<0.01)$. Dies läßt vermuten, daß den Messungen für Blattproben folgend SCMR die Bestimmung von SLA wiedergeben kann. Es gab signifikante Beziehungen zwischen SLN und SCMR ( $r=0,84$, $\mathrm{P}<0.01)$ sowie SLN und SLA $(\mathrm{r}=0,81, \mathrm{P}<0.01)$. Diese signifikanten Beziehungen zwischen SLA, SLN und SCMR zeigen, daß SCMR als ein zuverlässiger Meßwert verwendet werden kann, um Genotypen mit geringem SLA oder hohem SLN 8 und damit hohem (TE) bei Erdnuß zu erfassen.

\section{References}

Araus, J. L., J. Bort, S. Caccareli, and S. Grando, 1997: Relationship between leaf structure and carbon isotope discrimination in field grown barley. Plant Physiol. Biochem. 35, 533-541.

Bell, M. J., G. C. Wright, and G. L. Hammer, 1992: Night temperature affects radiation use efficiency in peanut. Crop Sci. 32, 1329-1335.

Branch, W. D., and G. L. Hildebrand, 1989: Pod yield comparison of pure line peanut selections simultaneously developed from Georgia and Zimbabwe breeding programs. Plant Breed. 102, 260-263.

Chapman, S. C., and H. J. Barreto, 1997: Using a chlorophyll meter to estimate specific leaf nitrogen of tropical maize during vegetative growth. Agron. J. 89, $557-562$.

Chatterton, N. J., D. R. Lee, and W. E. Hungerford, 1972: Diurnal change in SLW of Medicago sativa L. and Zea mays L. Crop Sci. 12, 576-578.

Cooper, M., and G. L. Hammer (eds), 1996: Plant Adaptation and Crop Improvement. CAB International, Wallingford.

Dwyer, L. M., A. M. Anderson, B. L. Ma, D. W. Stewart, M. Tollenaar, and E. Gregorich, 1995: Quantifying the nonlinearity in chlorophyll meter response to corn leaf nitrogen concentration. Can. J. Plant Sci. 75, 179-182.

Friend, D. J. C., 1966: The effect of light and temperature on the growth of cereals. In: F. L. Milthrope, and J. D. Ivins (eds), The Growth of Cereals and Grasses, pp. 181-199. Butterworths, London. 
Friend, D. J. C., V. A. Helson, and J. E. Fisher, 1962: Leaf growth in Marquis wheat as regulated by temperature, light intensity and day length. Can. J. Bot. 40, 1299-1311.

Hall, A. E., R. G. Mutters, and G. D. Farquhar, 1992: Genotypic and drought-induced differences in carbon isotope discrimination and gas exchange of cowpea. Crop Sci. 32, $1-6$.

Hubick, K. T., and Farquhar, 1987: Carbon isotope discrimination - selecting for water use efficiency. Aust. Cotton Grower 8, 66-68.

Hubick, K. T., G. D. Farquhar, and R. Shorter, 1986: Correlation between water-use efficiency and carbon isotope discrimination in diverse peanut germplasm. Aust. J. Plant Physiol. 13, 803-816.

Ma, B. L., M. J. Morrison, and H. D. Voldeng, 1995: Leaf greenness and photosynthetic rates in soybean. Crop Sci. 35, 1411-1414.

Mackown, C. T., and T. G. Sutton, 1998: Using earlyseason leaf traits to predict nitrogen sufficiency of burley tobacco. Agron. J. 90, 21-27.

Nageswara Rao, R. C., and G. C. Wright, 1994: Stability of the relationship between specific leaf area and carbon isotope discrimination across environments in peanut. Crop Sci. 34, 98-103.

Nageswara Rao, R. C., M. Udaykumar, G. D. Farquhar, H. S. Talwar, and T. G. Prasad, 1995: Variation in carbon isotope discrimination and its relationship to specific leaf area and ribulose-1,5-bisphosphate carboxylase content in groundnut genotypes. Aust. J. Plant Physiol. 22, 545-551.

Rawson, H. M., P. A. Gardner, and M. J. Long, 1987: Sources of variations in specific leaf area in wheat grown at high temperature. Aust. J. Plant Physiol. 14, $287-298$.

Rayment, G. E., and F. R. Higginson, 1992: Australian Laboratory Handbook of Soil and Water Chemical Analyses. Inkata Press, Sydney.
Reddy, V. R., B. Acock, D. N. Baker, and M. Acock, 1989: Seasonal leaf area-leaf weight relationship in the cotton canopy. Agron. J. 81, 1-4.

Reeves, D. W., P. L. Mask, C. W. Wood, and D. P. Delaney, 1993: Determination of wheat nitrogen status with a hand-held chlorophyll meter: influence of management practices. J. Plant Nutr. 16, $781-796$.

Smartt, J. (ed.), 1994: The Groundnut Crop - a Scientific Basis for Improvement. Chapman \& Hall, London.

Takebe, M., T. Yoneyama, K. Inada, and T. Murakam, 1990: Spectral reflectance ratio of rice canopy for estimating crop nitrogen status. Plant Soil 122, 295-297.

White, D. S., 1998: Potential for improving the drought resistance of soybean (Glycine max (L.) Merr) using the transpiration efficiency trait. M.Ag.Sc. Thesis, University of Adelaide, Adelaide.

Wright, G. C., and G. L. Hammer, 1994: Distribution of nitrogen and radiation use efficiency in peanut canopies. Aust. J. Agric. Res. 45, 565-574.

Wright, G. C., K. T. Hubick, and G. D. Farquhar, 1988: Discrimination in carbon isotopes of leaves correlates with water-use efficiency of field grown peanut cultivars. Aust. J. Plant Physiol. 15, 815-825.

Wright, G. C., R. C. Nageswara Rao, and G. D. Farquhar, 1994: Water-use efficiency and carbon isotope discrimination in peanut under water deficit conditions. Crop Sci. 34, 92-97.

Wright, G. C., R. C. Nageswara Rao, and M. S. Basu, 1996: A physiological approach to the understanding of genotype by environment interactions - A case study on improvement of drought adaptation in peanut. In: M. Cooper, and G. L. Hammer (eds), Plant Adaptation and Crop Improvement, pp. 365-381. CAB International, Wallingford. 